\title{
CORRELATION OF ANTI-INFLAMMATORY ACTIVITY WITH PHENOLIC CONTENT IN THE LEAVES OF Syzygium cumini (L.) SKEELS (MYRTACEAE)
}

\author{
Lucilene Azevedo Lima \\ Departamento de Produtos Naturais, Instituto de Tecnologia em Fármacos, Fundação Oswaldo Cruz, Rua Sizenando Nabuco, \\ 100, 21041-250 Rio de Janeiro - RJ. Departamento de Química Analítica, Instituto de Química, Universidade Federal do Rio \\ de Janeiro, Cidade Universitária, Ilha do Fundão, 21949-900 Rio de Janeiro - RJ, Brasil \\ Antonio Carlos Siani \\ Departamento de Produtos Naturais, Instituto de Tecnologia em Fármacos, Fundação Oswaldo Cruz, Rua Sizenando Nabuco, \\ 100, 21041-250 Rio de Janeiro - RJ, Brasil \\ Fabíola Almeida Brito, André Luís Franco Sampaio and Maria das Graças Müller Oliveira Henriques \\ Departamento de Farmacologia Aplicada, Instituto de Tecnologia em Fármacos, Fundação Oswaldo Cruz, Rua Sizenando \\ Nabuco, 100, 21041-250 Rio de Janeiro - RJ, Brasil \\ Carlos Alberto da Silva Riehl* \\ Departamento de Química Analítica, Instituto de Química, Universidade Federal do Rio de Janeiro, Cidade Universitária, Ilha \\ do Fundão, 21949-900 Rio de Janeiro - RJ, Brasil \\ Recebido em 2/5/06; aceito em 6/10/06; publicado na web em 28/5/07

\begin{abstract}
Phenolic contents of extracts of Syzygium cumini leaves, collected monthly over a one-year period, were quantitatively determined by the modified Folin-Ciocalteau method. Extracts and tannin-free fractions were assayed by their potential to inhibit mouse paw edema induced by C48/80. HPLC showed high molecular weight phenolic species and flavonoids in the active extracts and fractions. The highest total phenolic content corresponded to the most potent degree of inhibition and the flavonoids were supposed to be the main species responsible for the activity, given that the flavonoid-enriched ethyl-acetate fraction maintained its effect down to
\end{abstract} \\ a dose of $0.01 \mu \mathrm{g} / \mathrm{kg}$ in a dose-response manner.
}

Keywords: Syzygium cumini; seasonal variation; anti-inflammatory.

\section{INTRODUCTION}

Syzygium cumini (L.) Skeels (syn. Eugenia jambolana Lamark, Myrtaceae) is a tropical evergreen tree, originating from India and Sri Lanka, which usually reaches a height of 7 to $10 \mathrm{~m}$. It grows spontaneously in warm localities and is widespread in Brazil, where it is popularly known as "jamelão", "jambolão" or "azeitona" because of its olive-shaped fruit. Bark, leaves and fruits of S. cumini have been used in traditional medicine since ancient times ${ }^{1,2}$. Extracts of $S$. cumini are well known as hypoglycemic and antidiabetic agents, although results of pre-clinical or clinical studies have been controversial ${ }^{3-8}$, and they are also described for their diuretic $^{9}$, bactericidal ${ }^{10,11}$ and anti-inflammatory ${ }^{12-14}$, and for treatment of dysentery ${ }^{15}$. The leaves are rich in tannins $s^{3,16}$, flavonoids ${ }^{17,18}$, and essential oils ${ }^{11,19}$. Phenolic contents of leaves, bark and fruits are correlated with antioxidant activity ${ }^{20,21}$. Antiinflammatory and anti-ulcerogenic activities have been described for the ethanolic extract of the stem bark ${ }^{22}$. These effects, however, have not been correlated with any particular chemical constituent or class of compounds, although some isolated compounds from $S$. cumini have been elsewhere described as anti-inflammatory agents ${ }^{23}$.

The present study analyses the content of total phenols, tannins, simple phenols, and flavonoids in the leaves of S. cumini, collected monthly over a one-year period, by the Folin-Ciocalteau method. The values are correlated with the anti-inflammatory activity of the extracts, in the mouse paw edema model induced by $\mathrm{C} 48 / 80$.

*e-mail: riehl@iq.ufrj.br

\section{RESULTS AND DISCUSSION}

The results of absorbance values for different tannic acid concentrations are summarized in Table 1. The linear correlation in the concentration range assayed for the determination of tannic acid $(95 \%$ confidence interval $\mathrm{p}<0.05$, Table 2 ) allowed quantifying properly TP, SP and TT compounds (Figure 1). The choice of FolinCiocalteau's reagent (which contains sodium molybdate and sodium tungstate solutions) for the quantification of phenolic compounds was based on the fact that it is more sensitive and more precise than other methods described ${ }^{16,24}$, especially in view of the fact that, in plants, these constituents are usually found as heteroside derivatives, soluble in water and other polar solvents. Thus, a wide range of phenolic compounds is quantified with basis on their ability to react with oxidizing agents to produce compounds that absorb at specific wavelength. After measurement of total phenolic

Table 1. Absorbance values at $725 \mathrm{~nm}$ for different tannic acid concentrations (Folin-Ciocalteau method)

\begin{tabular}{llllll}
\hline TA (mg) & \multicolumn{3}{c}{ Absorbance (AU) } & M & V \\
\hline 0.0096 & 0.182 & 0.179 & 0.181 & 0.181 & 0.004 \\
0.0192 & 0.307 & 0.303 & 0.305 & 0.305 & 0.005 \\
0.0288 & 0.460 & 0.460 & 0.461 & 0.460 & 0.001 \\
0.0384 & 0.533 & 0.538 & 0.537 & 0.536 & 0.007 \\
0.0480 & 0.735 & 0.737 & 0.739 & 0.737 & 0.005 \\
\hline
\end{tabular}

$\mathrm{TA}=$ tannic acid, $\mathrm{AU}=$ absorbance unit, $\mathrm{M}=$ Mean value, $\mathrm{V}=$ Variance $(\mathrm{n}=3, \mathrm{t}=4.303, \mathrm{a}=0.05 \%)$. 
compounds at this wavelength, the ability of condensed polymeric tannins to bind to water-insoluble PVPP allows their removal and the quantification of the simple phenolics alone. The average observed values for the TP, simple phenolic SP and TT contents in the $S$. cumini aqueous extracts, calculated by the Folin-Ciocalteau method, are shown in Figure 2. The maximum content of phenolic compounds and tannins occurred from November to January. A progressive increase in TP from September to December-January can be clearly noticed. From February-March onwards there was a tendency for the TP to decrease progressively on average until JulyAugust. At a less extent, the same trend in the variation of TP is also accompanied by the average of total condensed tannin (TT), but this is evidently inverted in the case of simple phenols (SP), given that their contents in the leaves complement to afford TP values. The relative variation ranges for TT and SP are narrower than those observed for TP; the largest differences again occurring just before the rainy season (from October to January) (Figure 2). As expected, the MIX extract, obtained from mixing the extracts from November, December and January collections (from a single specimen), showed average TP values of $29.8 \%$ and TT values of

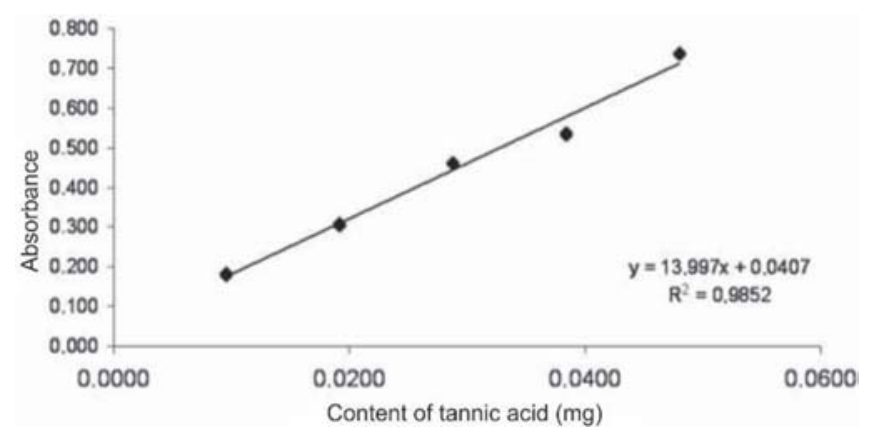

Figure 1. Analytical curve of tannic acid at $725 \mathrm{~nm}$ (Folin-Ciocalteau method) for different weighs (calculated from the stock solutions concentrations). Absorbance in $A U$ (absorbance unity)

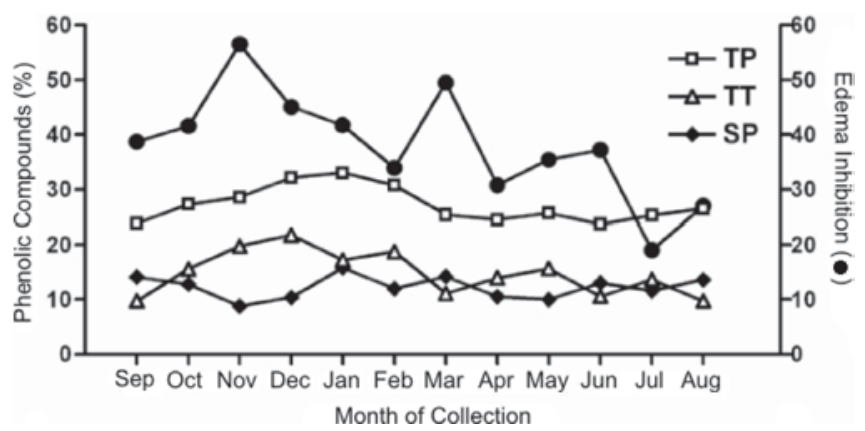

Figure 2. Content of total phenolic (TP), tannins (TT) and simple phenolic $(S P)$ compounds in Syzygium cumini aqueous leaf extract according to the period of collection plotted against the inhibition of C48/80-induced edema. Treatment $(50 \mathrm{mg} / \mathrm{kg}$ ) made $1 \mathrm{~h}$ before stimulation with C48/80 compound (100 ng/paw)
$18.3 \%$. After partition with ethyl acetate, these average values rose to $63.0 \%$ and $25.1 \%$, for TP and TT, respectively (Figure 3 ).


Figure 3. (a) Content in total phenolic compounds (TP) and tannins (TT) in Syzygium cumini MIX extract and MIX-AC fraction as determined by the Folin-Ciocalteau method and (b) inhibition of C48/80-induced (100 ng/paw) edema by MIX and MIX-AC (50 mg/kg; injected $1 \mathrm{~h}$ before stimulation)

The crude aqueous extract yields were around $7.4 \%(\mathrm{w} / \mathrm{w})$; the highest values being obtained for the collections from December to February. The peak distribution through the HPLC fingerprinting profile was consistent with the presence of hydrolysable tannins and flavonoids, and was highly similar for all the extracts. Basically, the peaks were grouped in three regions based on typical generic patterns of UV absorption, supporting the presence of ellagitannins (10 - 12 min) gallotannins $(12-25 \mathrm{~min})$ and flavonoids $(25-37 \mathrm{~min})^{25}$. The maximum content of phenolic compounds and tannins occurred from November to January, an event coincident with the period of transition from spring to summertime (beginning of the rainy season) in the southern hemisphere. As expected, the highest anti-inflammatory activity was coincident with increased levels of phenolic compounds. As in the case of the total phenolic compounds, a direct correlation was observed between the inhibitory activity and the content of total tannin. The average TT contents were also higher in the period between November and February; which also meant that the highest degree of inhibition corresponded to the lowest level of simple phenolic content. This fact reinforces the hypothesis of chemically defined compounds as responsible for the anti-inflammatory activity, which is further confirmed by the increasing inhibition observed by the ethyl acetate partitioning of the aqueous extract.

Analysis of the anti-inflammatory activity of Syzygium cumini aqueous crude extract was evaluated in a period of over one year in the C48/80 paw edema model, using a standard anti-inflammatory drug, sodium diclofenac, as the positive control. In the first month of

Table 2. Parameters from the analytical curve of tannic acid using ANOVA

\begin{tabular}{lcccccc}
\hline Source of Variance & SDQ & Df & Variance & Test F & $P$ & P \\
\hline Between Groups & 0.549 & 4 & 0.137 & 38896.349 & $6.578 \mathrm{E}-21$ & 3.478 \\
Within Groups & $3.533 \mathrm{E}-05$ & 10 & $3.533 \mathrm{E}-06$ & & & \\
Total & 0.549 & 14 & & & & \\
\hline
\end{tabular}

$\mathrm{SDQ}=$ sum of squares, $\mathrm{Df}=$ degrees of freedom, $\mathrm{P}=$ percentage of contribution. Variance "between groups" are defined by the triplicate values obtained for the same concentration; and "within groups" by all the values obtained for all the concentrations. 
analysis (September) treatment with $S$. cumini aqueous crude extract led to a $38.7 \%$ average inhibition of the paw edema. In the subsequent months, the anti-inflammatory activity of the extract increased to a maximum of $56.5 \%$ average inhibition in November and $45.1 \%$ in December. The inhibitory activity of the crude extracts decreased in February, maintaining a steady level $(30-40 \%)$ until May, and falling again in July (19.0\%) and August (27.0\%) (Figure 2). An odd inhibition peak was produced by the March extract, but the value $(49.3 \%)$ was averaged from only two measurements in this case. The SP content was also relatively higher (37.9\%) in the MIX-AC when compared to the aqueous MIX extract (11.4\%). HPLC experiments showed clearly that the fraction MIX-AC is not only specially enriched in SP, but in flavonoid compounds specifically (8-10 and 26-28\% of flavonoids in MIX and MIX-AC respectively; from the relative area peaks in the chromatograms obtained under identical conditions - data not shown). At the highest dose used in the experiments $(50 \mathrm{mg} / \mathrm{kg})$, the MIX extract and the enriched fraction MIX-AC exhibited the same pattern of edema inhibition despite the differences in phenolic content (Figure $3 \mathrm{a}$ and $3 \mathrm{~b}$ ). However, as illustrated in the dose-response experiments (Figure 4a) the treatment with MIX in higher doses $(100,10,1$ and $0.1 \mathrm{mg} / \mathrm{kg})$ inhibited the paw edema formation triggered by C48/80, $(43,40,32,30 \%$ of inhibition, respectively) at similar extents to treatment with an non steroidal anti-inflammatory drug sodium diclofenac (40\% of inhibition). This anti-inflammatory is widely used to relieve symptoms of inflammatory processes, due to its ability to inhibit prostaglandins and thromboxanes formed from arachidonic acid by cyclooxigenases (COXs) including the inducible isoform, COX 2 that is produced by mast cells and involved in allergic response. Reinforcing the inhibitory effect presented by MIX, the pre-treatment with MIX -AC (Figure 4b), in all doses used, was able to reduce about $35 \%$ of paw edema of inhibition, comparable to sodium diclofenac-treatment $(32 \%)$. Interestingly the inhibitory effect of MIX-AC was maintained down to a $10^{4}$ times lower dose $(0.01 \mu \mathrm{g} /$ $\mathrm{kg}$ ) than that necessary for the MIX extract. The literature reports a dose-related (100 to $1000 \mathrm{mg} / \mathrm{kg}$ ) inhibitory effect (13.3 to $44.4 \%$ ) for the ethanolic extract of $S$. cumini bark on the paw edema triggered by carrageenin, kaolin-carrageenin (up to a 24-h observation period), or formaldehyde (up to 48-h observation period); as well as in the cotton pellet granuloma test ${ }^{14}$. That is about twice the necessary dose reported in this study for the $66.2 \%$ inhibition by the leaf crude extract of the C48/80-induced edema. Oral administration of ethanolic extract of $S$. cumini bark also presented anti-inflammatory activity in histamine, 5-hydroxytriptamine and prostaglandin $\mathrm{E}_{2}$-induced rat paw edema ${ }^{15}$. In contrast with the bark, S. cumini leaf extract is reported to contain flavonoids ${ }^{17,18}$. The anti-inflammatory activity has been correlated with the presence of similar flavonoids in the methanolic leaf extract of the closely related species Eugenia jambos ${ }^{23,26}$. This correlation is corroborated by the inhibitory effect observed with flavonoid-rich MIX-AC, which maintained activity over the dose range from 0.01 to $100 \mu \mathrm{g} / \mathrm{kg}$. This property was not observed with the MIX extract, although both extracts and a fraction exhibited very similar results at the dose of $50 \mathrm{mg} / \mathrm{kg}$. The most potent activity shown by the ethyl acetate fraction MIX-AC reinforces the presence of a defined chemical group (flavonoids; more soluble in the ethyl acetate fraction) as responsible for the anti-inflammatory activity observed with leaf extracts of S. cumini. Some isolated flavonoids and catechins are already described as possessing anti-inflammatory ${ }^{27}$, anti-allergic ${ }^{28,29}$ and analgesic ${ }^{30}$ activities. On the other hand, the oral administration of crude extracts of $S$. cumini containing quantified tannins has been associated to gastroprotective and anti-ulcerogenic effects in rats ${ }^{22}$. However, few known flavonoids had been previously isolated from $S$. cumini leaves ${ }^{17,18}$ or flowers ${ }^{31}$.
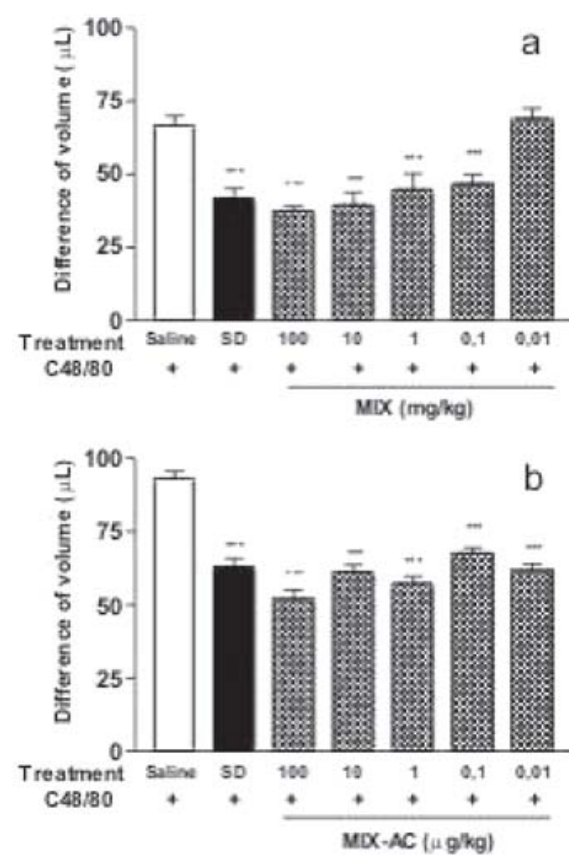

Figure 4. Inhibition of the C48/80 compound-induced paw edema after treatment with (a) MIX or (b) MIX-AC (0.01 $\mu \mathrm{g} / \mathrm{kg}$ to $100 \mathrm{mg} / \mathrm{kg}) ;$ sodium diclofenac $(S D ; 100 \mathrm{mg} / \mathrm{kg})$ as positive control. Results expressed as mean \pm S.E.M. of at least 6 animals. $* * * p<0.05$

\section{EXPERIMENTAL}

\section{Drugs and chemicals}

Induction agent C48/80, sodium diclofenac, polyvinylpyrrolidone (PVP), diphenylboryloxyethylamine and polyethyleneglicol (NP/PEG reagent) were purchased from Sigma (St. Louis, USA). FolinCiocalteau reagent and tannic acid were purchased from SigmaAldrich (Milwaukee, USA).

\section{Plant material and extracts}

Fresh leaves of Syzygium cumini were collected in the campus of the Oswaldo Cruz Foundation, Rio de Janeiro, Brazil, from three specimens, in the period from September 2002 to August 2003. The plant material was identified by Dr. G. M. Barrozo and a voucher specimen was deposited in the Herbarium of the Botanic Garden of Rio de Janeiro under $\mathrm{N}^{\circ}$. 380789. Leaves were extracted with boiling water during $20 \mathrm{~min}$ at a $6 \%(\mathrm{w} / \mathrm{v})$ ratio. After cooling, the solution was filtered, lyophilized (Christ Beta 1-15, Germany) and the extract was kept in a dry atmosphere. The crude extracts of the November, December and January collections (from a single specimen) were combined (MIX) and then partitioned with ethyl acetate to afford the MIX-AC fraction (15\%). Before combining the extracts, their chemical similarities were qualitatively checked by HPLC.

\section{Analytical High Performance Liquid Chromatography (HPLC)}

All the samples (monthly MIX and MIX-AC) were prepared by suspending 0.1 to $40 \mathrm{mg}$ (Sartorius BP2215, France) of the extracts or of tannic acid in acetone:water 7:3 (stock solution), respectively in $1.00 \mathrm{~mL}$ of distilled water in a $2 \mathrm{~mL}$ microcentrifuge tube. The suspensions were sonicated (Odontrobras 2840D, São Paulo, Brazil) for $5 \mathrm{~min}$ and then centrifuged at $2000 \mathrm{rpm}$ at $20^{\circ} \mathrm{C}$ (Beckman Coulter 
J6-MI, CA, USA). The soluble part was applied to silica gel chromatoplates $\mathrm{GF}_{254}(5 \mathrm{~cm})$, run in BAW (n-butanol: acetic acid: water 4:1:5) and tested for the presence of flavonoids with NP/PEG reagent. HPLC data were collected and processed on a Shimadzu model CLASS-VP 6.12 (Kyoto, Japan) equipped with a diode-array detector (DAD) and a SP3 chromatographic software. The mobile phase gradient elution was programmed for solvent A (acetonitrile: water 5:95, v/v) and solvent B (acetonitrile:water 90:10, v/v). The mobile phase was adjusted to $\mathrm{pH} 4.0$ with phosphoric acid. The reverse phase column (Supelcosil LC-18; $25 \mathrm{~cm} \times 4.6 \mathrm{~mm} \times 5 \mu \mathrm{m}$ ) was previously equilibrated with the mobile-phase for $30 \mathrm{~min}$ at a flow rate of $0.75 \mathrm{~mL} / \mathrm{min}$. The flow rate was maintained at $0.75 \mathrm{~mL} / \mathrm{min}$ and the injection volume $20 \mu \mathrm{L}$. The column temperature was maintained at $25{ }^{\circ} \mathrm{C}$ during analysis. The gradient program started with $0 \%$ of solvent B and then increased linearly to $100 \%$ of solvent $\mathrm{B}$ in $30 \mathrm{~min}$. Injections were performed in triplicate. After $44 \mathrm{~min}$, the elution program was returned to the initial condition and then held for $10 \mathrm{~min}$ in order to recondition the column.

\section{Analytical curve}

Tannic acid was used as an analytical standard for total phenol quantification. Working solutions were prepared from the stock standard solutions $(1.0 \mathrm{mg} / \mathrm{mL})$ to contain $0.00 ; 0.0096 ; 0.0192$; $0.0288 ; 0.0384$ and $0.0480 \mathrm{mg} / \mathrm{mL}$ of tannic acid in acetone:water 7:3. Tannic acid was quantified by the Folin-Ciocalteau method, and the samples (triplicates) were analyzed in a spectrophotometer (Molecular Devices SpectraMAX ${ }^{\circledR} 190$, CA, USA) at $725 \mathrm{~nm}$ (Figure 1). Tannic acid solutions were also quantified by HPLC (UV detection $)^{32}$ and the results were very similar to those obtained by the Folin-Ciocalteau procedure (data not shown).

\section{Determination of total phenolic (TP) compounds}

Extract samples with weights ranging from 0.1 to $20 \mathrm{mg}$ were diluted in $10.0 \mathrm{~mL}$ of acetone:water 7:3, cooled in an ice bath and sonicated during $20 \mathrm{~min}$ in a $15 \mathrm{~mL}$ centrifuge tube. Samples were then centrifuged for $10 \mathrm{~min}\left(3000 \mathrm{rpm}\right.$ at $\left.4{ }^{\circ} \mathrm{C}\right)$. The soluble part was decanted, kept under refrigeration at $7{ }^{\circ} \mathrm{C}$, and eventually diluted to fall within the optimum concentration range, represented by the analytical curve. Fifty microliters of the soluble part of each sample and $450 \mu \mathrm{L}$ of distilled water were stirred in a test tube in triplicate. The mixtures were quantified by the Folin-Ciocalteau method and analyzed in a spectrophotometer at $725 \mathrm{~nm}$. Total phenolic content (TP) was calculated based on the tannic acid analytical curve, and expressed as a percentage of the dry material weight. Averages for TP, TT (total tannins) and SP (simple phenolics) values were considered, regarding the three specimens monthly collected.

\section{Determination of simple phenolic (SP) and total tannins (TT) content}

In a test tube, $100 \mathrm{mg}$ of polymer polyvinylpolypyrrolidone (PVPP), $1 \mathrm{~mL}$ of distilled water and $1 \mathrm{~mL}$ of the crude extract were stirred, cooled at $0-5{ }^{\circ} \mathrm{C}$ for $15 \mathrm{~min}$, stirred once more and centrifuged for $10 \mathrm{~min}\left(3000 \mathrm{rpm}\right.$ at $\left.4{ }^{\circ} \mathrm{C}\right)$. The suspension was decanted and the soluble part, containing only the SP compounds (tannins were adsorbed to the polymer), was analyzed. A hundred microliters of the soluble part, containing only the SP compounds of each sample and $400 \mu \mathrm{L}$ of distilled water were stirred in a test tube in triplicate. The mixture was quantified by the FolinCiocalteau method and analyzed in a spectrophotometer at $725 \mathrm{~nm}$. Total SP content was calculated with reference to the tannic acid analytical curve, and expressed on the basis of the dry material. The difference between the TP and SP afforded the total highmolecular TT in the sample.

\section{Induction of paw edema and treatment}

Male Swiss mice (18-25 g; groups of 7 animals), from the Oswaldo Cruz Foundation colony were housed in a room with controlled temperature $\left(23 \pm 2{ }^{\circ} \mathrm{C}\right)$ and lighting (lights on from 7:00 to 19:00 h), with free access to lab chow and tap water. All the experiments were carried out in total accordance with the institutional Ethical Committee guidelines (Institutional license No. 0050/00). Mouse paw edema was induced as described by Henriques et al..$^{33}$ and C48/80 used as edematogenic agent according to Stochla ${ }^{34}$. Briefly, animals received a sub plantar injection of C48/80 (100 ng/ paw), the other paw received the same volume of sterile saline (50 $\mu \mathrm{L})$. Edema was evaluated $30 \mathrm{~min}$ after C48/80 stimulation (100 ng/ paw) in a digital plethismometer (Ugo Basile, Italy). The edema was estimated as the difference of volumes $(\mu \mathrm{L})$ between the stimulated and the saline-injected paw. S. cumini leaf aqueous crude extract $(0.01-100 \mathrm{mg} / \mathrm{kg})$, fraction $(0.01-100 \mu \mathrm{g} / \mathrm{kg})$ or the reference drug sodium diclofenac $(100 \mathrm{mg} / \mathrm{kg})$ were administered orally $(200 \mu \mathrm{L}) 1$ $\mathrm{h}$ before sub-plantar stimulation with $\mathrm{C} 48 / 80$ in animals submitted to previous fast for $12 \mathrm{~h}$. Animals received lab chow only $1 \mathrm{~h}$ after the different treatments. Data were expressed as the mean \pm S.E. Averages and standard deviations were calculated and the data were submitted to statistical analysis by ANOVA (analysis of variance), followed by Student's t-test ${ }^{35}$ or Newman Keuls test, using the confidence intervals of $95 \%(\mathrm{p}<0.05)$.

\section{CONCLUSIONS}

Besides confirming the direct correlation between the total phenolic and flavonoid compounds in the leaf extract of S. cumini and the anti-edematogenic activity, the current study also established the best period to gather the raw material, for maximum therapeutic properties in a potential anti-inflammatory phytomedicine. The adequacy of the Folin-Ciocalteau method for the quantification of phenolic compounds is moreover demonstrated for a first chemical control of phytopharmaceuticals derived from Syzygium cumini. The maximum concentration of phenolic compounds in the leaves occurred from the end of spring to the beginning of the summer in South America (November to January), a period when the leaves reach maturity. Factors related to leaf ageing may support our findings and suggest that the decrease in leaf phenolic content in $S$. cumini is related to a series of genetic events that correlate to a complex aging system which regulates the nature and abundance of the metabolites. These would include internal and external stimuli such as luminosity rate, pluviometric indices, pathogenic stimuli, hormones and others ${ }^{36,37}$.

\section{ACKNOWLEDGEMENTS}

Authors would like to thank biologist S. S. Monteiro for the $S$. cumini collection and exsiccate preparation. This study was partially supported by grants from $\mathrm{CNPq}$, Brazil.

\section{REFERENCES}

1. Corrêa P.; Dicionário das Plantas Úteis do Brasil e das Exóticas Cultivadas, $2^{\text {a }}$ ed., Ed. Imprensa Nacional, Ministério da Agricultura: Rio de Janeiro; 1984, vol. 4, p. 429.

2. Sagrawat, H.; Mann, A. S.; Kharya, M. D.; Phcog. Mag. 2006, 2, 96.

3. Bhatia, I. S.; Bajaj, K. L.; Planta Med. 1975, 28, 346. 
4. Teixeira, C. C.; Rava, C. A.; da Silva, P. M.; Melchior, R.; Argenta, R.; Anselmi, F.; Almeida, C. R.; Fuchs, F. D.; J. Ethnopharmacol. 2000, 71, 343.

5. Vikrant, V.; Grover, J. K.; Tandon, N.; Rathi, S. S.; Gupta, N.; J. Ethnopharmacol. 2001, 76, 139.

6. Sharma, S. B.; Nasir, A.; Prabhu, K. M.; Murthy, P. S.; Dev, G.; J. Ethnopharmacol. 2003, 85, 201.

7. Grover, J. K.; Vats, V.; Rathi, S. S.; Dawar, R.; J. Ethnopharmacol. 2001 $76,233$.

8. Sridhar, S. B.; Sheetal, U. D.; Shastri, M. S.; Braz. J. Med. Biol. Res. 2005, $38,463$.

9. Silva-Netto, R. C.; Lopes, R. A.; Pozetti, G. L.; Rev. Fac. Odont. Ribeirão Preto, 1986, 23, 213

10. Damasceno, D. C.; Lima, P. H. O.; Galhiane, M. S.; Volpato, G. T.; Rudge, M. V.; Rev. Bras. Plantas Medicinais 2002, 4, 46.

11. Shafi, P. M.; Rosamma, M. K.; Jamil, K.; Reddy, P. S.; Fitoterapia 2002 , $73,414$.

12. Chaudhuri, A. K. N.; Pal, S.; Gomes, A.; Battacharya, S.; Phytotherapy Res. 1990, 4, 5

13. Muruganandan, S.; Srinivasan, K.; Chandra, S.; Tandan, S. K.; Lal, J.; Raviprakash, V.; Fitoterapia 2001, 72, 369.

14. Muruganandan, S.; Pant, S.; Srinivasan, K.; Chandra, S.; Tandan, S. K.; Lal, J.; Prakash, R. V.; Indian J. Physiol. Pharmacol. 2002, 46, 482.

15. Glyphis, J. P.; Puttick, G. M.; Phytochemistry 1998, 27, 743.

16. Mukherjee, P. K.; Saha, K.; Murugesan, T.; Mandal, S. C.; Pal, M.; Saha, B. P.; J. Ethnopharmacol. 1998, 60, 85.

17. Mahmoud, I. I.; Marzouk, M. S.; Moharram, F. A.; El-Gindi, M. R.; Hassan, A. M.; Phytochemistry 2001, 58, 1239.

18. Timbola, A. K.; Szpoganicz, B.; Branco, A.; Monache, F. D.; Pizzolatti, M. G.; Fitoterapia 2002, 73,174.
19. Khanna, R. K.; Indian Perf. 1991, 112.

20. Banerjee, A.; Dasgupta, N.; De, B.; Food Chem. 2005, 90, 727.

21. Bajpai, M.; Pande, A.; Tewari, S. K.; Prakash, D.; Int. J. Food Sci. Nutr. 2005, 56, 287

22. Ramirez, R. O.; Roa Jr., C. C.; Clin. Hemorheol. Microcirc. 2003, 29, 253.

23. Slowing, K.; Carretero, E.; Villar, A.; Phytotherapy Res. 1996, 10, S-126.

24. Julkunen-Tiito, R.; J. Agric. Food Chem. 1985, 33, 213.

25. Scott, A. I. Em International Series of Monographs on Organic Chemistry; Barton, D. H. R.; Doering, W., eds.; Pergamon Press: Oxford, 1964, vol. 7.

26. Slowing, K.; Sollhuber, M.; Carretero, E.; Villar, A.; Phytochemistry 1994, $37,255$.

27. Ueda, H.; Yamazaki, C.; Yamazaki, M.; Biol. Pharm. Bull. 2002, 25, 1197.

28. Cheong, H.; Ryu, S. Y.; Oak, M. H.; Cheon, S. H.; Yoo, G. S.; Kim, K. M.; Arch. Pharmacal. Res. 1998, 21, 478.

29. Sano, M.; Suzuki, M.; Myiase, T.; Yoshino, K.; Maeda-Yamamoto, M.; $J$. Agric. Food Chem. 1999, 471, 906.

30. Chou, T. C.; Chang, L. P.; Li, C. Y.; Wong, C. S.; Yang, S. P.; Anesth. Analg. 2003, 97, 1724

31. Subramanian, S. S.; Nair, A. G. R.; Curr. Science 1972, 703

32. Escarpa, A.; Gonzalez; M. C.; J. Chromatogr., A 2000, 897, 161.

33. Henriques, M. G. M. O.; Silva, P. M. R.; Martins, M. A.; Flores, C. A.; Cunha, F. Q.; Assurey-Filho, J.; Cordeiro, R. S. B.; Braz. J. Med. Biol. Res. 1987, 20, 243.

34. Stochla, K.; Acta Phys. Pol. 1980, 31, 535.

35. Millar, J. N.; Millar, J. C.; Statistics and Chemometrics for Analytical Chemistry, $4^{\text {th }}$ ed., Pearson Education: Paris, 2000.

36. Woodall, I. C.; Dodd, I. C.; Stewart, G. R.; J. Exp. Bot. 1998, 318, 79.

37. Hayden, D. M.; Christopher, D. A.; Plant Sci. 2004, 166, 779. 